\title{
Frequency of different types of stroke in pregnancy and puerperium: case studies from Moscow hospitals in 2017
}

\author{
D.D. Namestnikova1,2, I.L. Gubskiy¹, M.B. Shamanova², I.V. Platitsyn², V.A. Anufriyev³, M.A. \\ Loskutnikov $^{4}$, L.V. Gubsky ${ }^{1}$, N.A. Shamalov ${ }^{1}$ \\ ${ }^{1}$ Pirogov Russian National Research Medical University, Russia; ${ }^{2}$ Perinatal Medical Center, Moscow, \\ Russia; ${ }^{3}$ Yudina Moscow city hospital, Moscow, Russia; ${ }^{4}$ Vorohobov city hospital 67 , Moscow, Russia.
}

\section{Background and Aim}

Pregnancy and puerperium period are associated with an increased risk of stroke. Due to the various possible causes of cerebrovascular complications in women related and unrelated to pregnancy their diagnostic become challenging problem for neurologists and obstetricians. In this study we evaluated frequency, risk factors and causes of strokes in 3 obstetric hospitals in Moscow in 2017.

\section{Materials and Methods}

Prospective analysis (etiology, risk factors, treatment and outcome) of ischemic (IS) and hemorrhagic (HT) stroke, transient ischemic attack (TIA), cerebral venous thrombosis (CVT) cases in women $(n=16177)$ during pregnancy and postpartum period in 3 Moscow obstetric hospitals in 2017 was conducted.
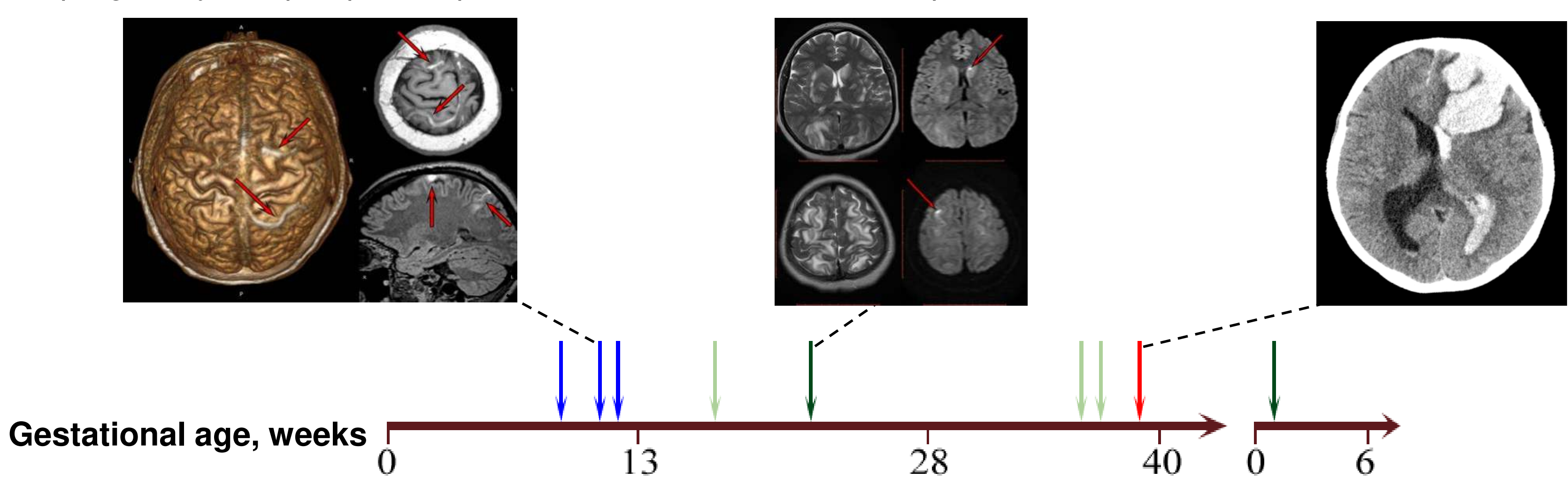

$\Longrightarrow$ TILA

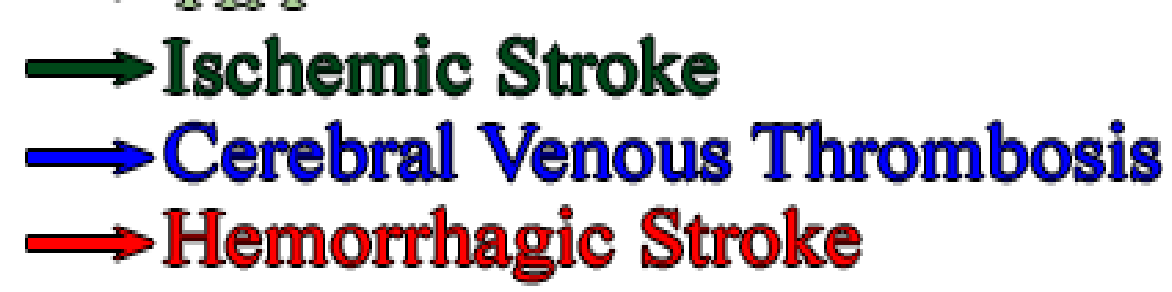

Postpartum period,

\section{Results}

The frequency of ischemic stroke was 2 per 16177 deliveries $(0.012 \%)$ : 1 case in patient with sever preeclampsia with PRES and 1 due to amniotic fluid embolism. For hemorrhagic stroke -1 patient with arteriovenous malformation per 16177 (0.006\%). For CVT - 3 per $16177(0.019 \%)$ and all patients had hereditary thrombophilia and onset in first trimester of pregnancy. Evaluation of TIA was carried out only in one hospital and observed in 3 patients with different risk factors for young stroke per $2715(0.110 \%)$.

\begin{tabular}{c|c|c|c|c} 
& Hospital 1 & Hospital 2 & Hospital 3 & Total \\
\hline Total number of birth in 2017 & 6427 & 7035 & 2715 & 16177 \\
\hline TIA & No data & No data & 3 & 3 \\
\hline Ischemic stroke & 1 & 1 & 0 & 2 \\
\hline Hemorrhagic stroke & 0 & 0 & 1 & 1 \\
\hline Cerebral venous thrombosis & 1 & 1 & 1 & 3 \\
\hline $\begin{array}{c}\text { Total number of } \\
\text { cerebrovascular disorders }\end{array}$ & 2 & 2 & 5 & 9
\end{tabular}

\begin{tabular}{c|c|c|c|c|c}
\multicolumn{2}{c|}{} & TIA & IS & HT & CVT \\
\hline \multirow{2}{*}{$\begin{array}{c}\text { Pregnancy-related } \\
\text { risk factors }\end{array}$} & Preeclampsia/Eclampsia & - & 1 & - & - \\
\cline { 2 - 7 } & Amniotic fluid embolism & - & 1 & - & - \\
\hline \multirow{4}{*}{$\begin{array}{c}\text { Other risk factors of } \\
\text { stroke in young } \\
\text { adults }\end{array}$} & $\begin{array}{c}\text { Recurrent } \\
\text { miscarriage/Antiphospholipid } \\
\text { syndrome }\end{array}$ & 1 & - & - & - \\
\cline { 2 - 7 } & Arterial hypertension & - & - & 1 & - \\
\cline { 2 - 7 } & Inherited thrombophilia & 3 & - & - & 3 \\
\cline { 2 - 7 } & Patent foramen ovale & 1 & - & - & - \\
\cline { 2 - 7 } & Arteriovenous malformation & - & - & 1 & -
\end{tabular}

\section{Conclusion}

Observed cases of ischemic stroke were associated with pregnancy-related complications, while TIA, hemorrhage and CVT were associated other risk factors of young stroke (hematological disorders and vascular abnormalities). 